\title{
CÉLULA A COMBUSTÍVEL MICROBIANA COM UM CONSÓRCIO DE MICRORGANISMOS UTILIZADOS NO TRATAMENTO DE VINHAÇA
}

\author{
V. F. PASSOS ${ }^{1}$, S. AQUINO NETO ${ }^{1}$, A. R. DE ANDRADE ${ }^{1}$, V. REGINATTO ${ }^{1}$ \\ ${ }^{1}$ Universidade de São Paulo, Faculdade de Filosofia Ciências e Letras de Ribeirão Preto, \\ Departamento de Química \\ E-mail para contato: vpassos@usp.br
}

\begin{abstract}
RESUMO - Nas células a combustível microbianas, a eletricidade é gerada a partir da oxidação de compostos orgânicos catalisada por microrganismos (ânodo), sendo os elétrons transferidos para um circuito externo anterior à etapa da redução por um aceitador de elétrons (cátodo). O que diferencia estas células são os microrganismos utilizados na oxidação e a natureza dos compostos orgânicos oxidados. Neste trabalho foi utilizado um consórcio de microrganismos anaeróbio usado no tratamento de vinhaça. Foram utilizados reatores com capacidade de $250 \mathrm{~mL}$, aos quais foi introduzido um tecido de carbono para o crescimento dos microrganismos. Os reatores foram alimentados com glicose por 98 dias, aumentando-se a concentração de glicose de 5 até $20 \mathrm{~g} \mathrm{~L}^{-1}$. Foram realizados testes eletroquímicos em um potenciostato, mensurando a densidade de potência. Os testes evidenciaram ciclos de aumento e decaimento dessa densidade de potência. A maior densidade de potência de $2,06 \mu \mathrm{W} \mathrm{cm}{ }^{-2}$ foi obtida com $10 \mathrm{~g} \mathrm{~L}^{-1}$ de glicose, sendo que acima desta concentração houve uma diminuição da densidade de potência.
\end{abstract}

\section{INTRODUÇÃO}

Uma das atuais preocupações ambientais é a substituição das atuais formas de geração de energia a partir de combustíveis fósseis, por sistemas menos poluentes.

Os sistemas biológicos para a produção de energia têm sido vistos com grande interesse, pois é possível utilizar águas residuárias e resíduos agroindustriais com elevada concentração de carboidratos como substratos. Desse modo, surgem como alternativas o desenvolvimento de células microbianas à combustível, ou em inglês Microbial Fuel Cell (MFC). O uso dessas células para esse fim envolve algumas reações, entre elas a de oxidação dos compostos orgânicos oriundos de resíduos agroindustriais, catalisada por microrganismos. Essa reação gera eletricidade através da transferência de elétrons para um circuito externo, introduzido antes da etapa da redução de um aceitador de elétrons, normalmente o oxigênio (Rachinski et al., 2010).

A estrutura de uma MFC consiste em basicamente dois compartimentos, os quais são separados por uma membrana que impede a difusão de $\mathrm{O}_{2}$ para o ânodo e permite a passagem dos prótons 
gerados para o cátodo. No compartimento anódico, um tecido de grafite abriga os microrganismos anaeróbios e o cátodo é um compartimento aeróbio onde os elétrons reduzem o $\mathrm{O}_{2}$ (receptor de elétrons). Esses dois eletrodos são conectados por um circuito elétrico externo - um potenciostato onde há trajetória dos elétrons para o aproveitamento de sua energia.

As reações 1 e 2 representam as reações que ocorrem no ânodo e no cátodo utilizando a glicose como matéria orgânica oxidável. No compartimento anaeróbio, ânodo, ocorre a oxidação da glicose, com formação de dióxido de carbono, prótons e elétrons (reação 1).

$$
\mathrm{C}_{6} \mathrm{H}_{12} \mathrm{O}_{6}+6 \mathrm{H}_{2} \mathrm{O} \rightarrow 6 \mathrm{CO}_{2}+24 \mathrm{H}^{+}+24 \mathrm{e}^{-} \text {(reação 1) }
$$

Dessa forma, os elétrons são transferidos diretamente para o eletrodo, fluindo em seguida para o cátodo. Os prótons formados são conduzidos para o cátodo (que é aberto), através da membrana permeável. No cátodo, o oxigênio do ar aceita esses elétrons e prótons e se reduz, formando água como produto.

$$
4 \mathrm{H}^{+}+\mathrm{O}_{2}+4 \mathrm{e}^{-} \rightarrow 2 \mathrm{H}_{2} \mathrm{O} \text { (reação 2) }
$$

Esse fluxo de elétrons gera uma corrente elétrica que pode ser mensurada e utilizada para realizar trabalho. Os microrganismos que crescem no tecido de grafite, localizado no ânodo, podem ser culturas puras ou culturas mistas (ou seja, consórcios de microrganismos), como lodos oriundos de sistemas biológicos de tratamento de efluentes (Pham et al., 2006). Lodos anaeróbios são considerados boas fontes de microrganismos exo-eletrogênicos, ou seja, capazes de transferir elétrons para fora da célula e por isto podem ser utilizados em MFC (Logan, 2009).

Neste sentido, neste trabalho, cultivou-se em biorreatores um consórcio de microrganismos oriundos de um reator anaeróbio utilizado no tratamento de vinhaça para a sua utilização como catalisadores biológicos em uma célula microbiana à combustível.

\section{MATERIAIS E MÉTODOS}

\subsection{Aparato Experimental}

Como inóculo da MFC, foi utilizado um lodo anaeróbio coletado de um reator de fluxo ascendente utilizado para o tratamento de vinhaça de uma usina de açúcar e etanol da Região de Ribeirão Preto/SP.

Frascos tipo Schott foram utilizados como biorreatores com capacidade de $250 \mathrm{~mL}$, aos quais foi adicionado um volume de $100 \mathrm{~mL}$ de lodo contendo inicialmente $12,9 \mathrm{~g} \mathrm{~L}^{-1}$ de sólidos voláteis (SV), conforme APHA et al. (2005), e $100 \mathrm{~mL}$ de meio de cultura, contendo glicose como fonte de carbono. $\mathrm{O}$ experimento foi feito em triplicata, utilizando um biorreator como controle. Os materiais 
suportes para o crescimento dos microrganismos eram tecidos de carbono de área igual a $5 \mathrm{~cm}^{2}$, os quais foram inseridos dentro de cada biorreator, através de um fio de cobre.

A alimentação dos biorreatores foi diária, por um período de 98 dias, através da retirada e reposição de $100 \mathrm{~mL}$ de solução de glicose com macro e micronutrientes, conforme Gonzalez-Gil et al. (2002). A concentração de glicose foi aumentada ao longo do período de acompanhamento dos biorreatores de 5 até $20 \mathrm{~g} \mathrm{~L}^{-1}$. Após a alimentação, o pH foi ajustado para 6,0 $( \pm 0,2)$ e argônio foi borbulhado no meio para assegurar as condições de anaerobiose. A temperatura dos biorreatores foi controlada constantemente por um banho termostatizado a $50^{\circ} \mathrm{C}$.

\subsection{Determinação dos Metabólitos dos Microrganismos}

A análise dos metabólitos oriundos da degradação anaeróbia da glicose, ou seja, os ácidos orgânicos e também o consumo de glicose durante o período de acompanhamento dos biorreatores foi feita em um equipamento de Cromatografia Líquida de Alta Eficiência (HPLC).

\subsection{Determinação dos Parâmetros Eletroquímicos na MFC}

O material suporte no qual os microrganismos cresceram foi retirado dos biorreatores semanalmente para a determinação dos parâmetros eletroquímicos em uma MFC. O ânodo da célula foi formado pelo tecido de carbono, onde houve o crescimento dos microrganismos (biofilme), colocado em um frasco de $50 \mathrm{~mL}$, contendo o meio de cultura e mantido sob condições anaeróbias. Esta célula era dividida ao meio por uma membrana trocadora de prótons (Nafion ${ }^{\circledR}$ ). $\mathrm{O}$ cátodo foi constituído de Pt-black $20 \%\left(\mathrm{M} / \mathrm{m}\right.$ ) com carga de platina de $0,5 \mathrm{~g} \mathrm{~cm}^{-2}$ (semelhante ao utilizado por Moehlenbrock e Minteer, 2008), conforme esquema mostrado na Figura 1.

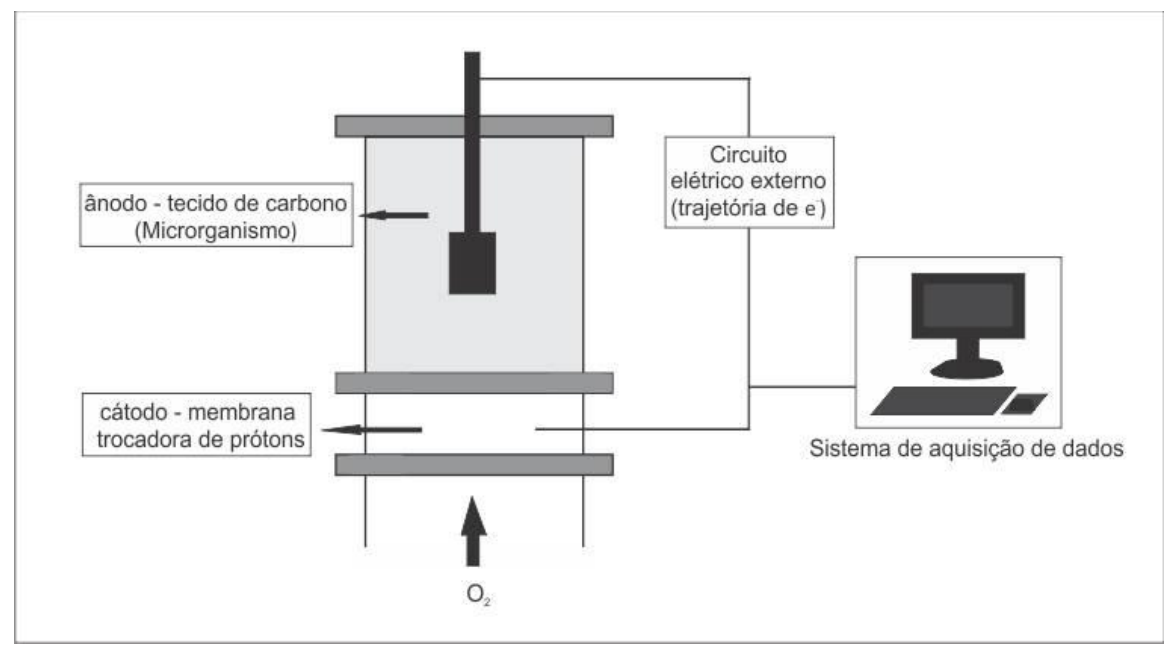

Figura 1. Esquema da MFC, utilizada nos testes eletroquímicos (Microbial Fuel Cell). 
Os testes eletroquímicos foram feitos em um potenciostato, o qual mede o potencial de circuito aberto e a densidade de potência da MFC. O potencial de circuito aberto se refere à energia do sistema, ou seja, a diferença de potencial entre ânodo e cátodo quando não está passando corrente no sistema. Já a densidade de potência é o valor da potência medida dividida pela área do biofilme, extraída da curva de polarização da biocélula em questão - ela se refere à diferença de potencial quando se aplica uma determinada corrente.

\section{RESULTADOS E DISCUSSÕES}

Na Tabela 1 estão apresentados os resultados de densidade de potência máxima aferida pelo potenciostato ao longo do tempo de operação dos biorretores.

Tabela 1 - Densidade de potência máxima e potencial de circuito aberto em relação ao tempo de acompanhamento dos biorreatores.

\begin{tabular}{ccc}
\hline Tempo (dias) & $\begin{array}{c}\text { Potencial de circuito } \\
\text { aberto }(\mathrm{V})\end{array}$ & $\begin{array}{c}\text { Potência máxima } \\
\left(\mu \mathrm{W} \mathrm{cm} \mathbf{~ c m}^{-2}\right)\end{array}$ \\
\hline $\mathbf{1 6}$ & -- & -- \\
$\mathbf{2 3}$ & -- & -- \\
$\mathbf{3 7}$ & 0,51 & $2,06( \pm 0,07)$ \\
$\mathbf{4 4}$ & 0,45 & $1,74( \pm 0,41)$ \\
$\mathbf{5 8}$ & 0,50 & $0,68( \pm 0,42)$ \\
$\mathbf{6 4}$ & 0,52 & $0,90( \pm 0,21)$ \\
$\mathbf{7 9}$ & 0,54 & $1,64( \pm 0,25)$ \\
$\mathbf{8 6}$ & 0,51 & $1,71( \pm 0,52)$ \\
$\mathbf{9 3}$ & 0,40 & $1,07( \pm 0,17)$ \\
$\mathbf{9 8}$ & 0,35 & $0,90( \pm 0,12)$ \\
\hline
\end{tabular}

Durante os primeiros 23 dias de experimento não foi possível mensurar qualquer densidade de potência, pois visualmente não era possível verificar nenhuma aderência dos microrganismos ao tecido de carbono.

A partir do $37^{\circ}$ dia de acompanhamento dos biorreatores foi possível medir uma densidade de potência de $2,06 \mu \mathrm{W} \mathrm{cm} \mathrm{cm}^{-2}$, a qual permaneceu relativamente constante até o $44^{\circ}$ dia de monitoramento. Após este período, foi observado um decréscimo da densidade de potência para 0,68 $\mu \mathrm{W} \mathrm{cm}{ }^{-2}$, seguido de um novo aumento entre os dias 79 e $86\left(1,64\right.$ e 1,71 $\mu \mathrm{W} \mathrm{cm}^{-2}$, respectivamente), próximo aos valores observados anteriormente. Nos dias 93 e 98 foi observada uma nova queda da densidade de potência. Portanto, o comportamento observado pareceu ser cíclico, ou seja, um aumento seguido por um decaimento da densidade de potência. Este comportamento pode ser consequência do crescimento e decaimento dos microrganismos do biofilme formado sobre o tecido de carbono. 
As determinações de SV realizadas no início e após 40 dias revelaram um decréscimo da concentração dos sólidos em suspensão de $12,9 \mathrm{~g} \mathrm{~L}^{-1}$ para $3,30 \mathrm{~g} \mathrm{~L}^{-1}$, provavelmente devido à substituição diária do sobrenadante dos biorreatores durante a alimentação e à adesão dos microrganismos ao biofilme.

A Figura 2 ilustra o comportamento da densidade de potência nos biorreatores em relação à concentração de glicose aplicada na alimentação dos biorreatores, ao longo do tempo. Estes resultados demonstram os ciclos de aumento e decaimento de densidade de potência, em função da concentração de glicose. Nesta figura pode-se observar que logo após o aumento da concentração de glicose houve um aumento da densidade de potência e nos períodos nos quais a concentração de glicose permaneceu constante ocorreu um decréscimo dessa densidade.

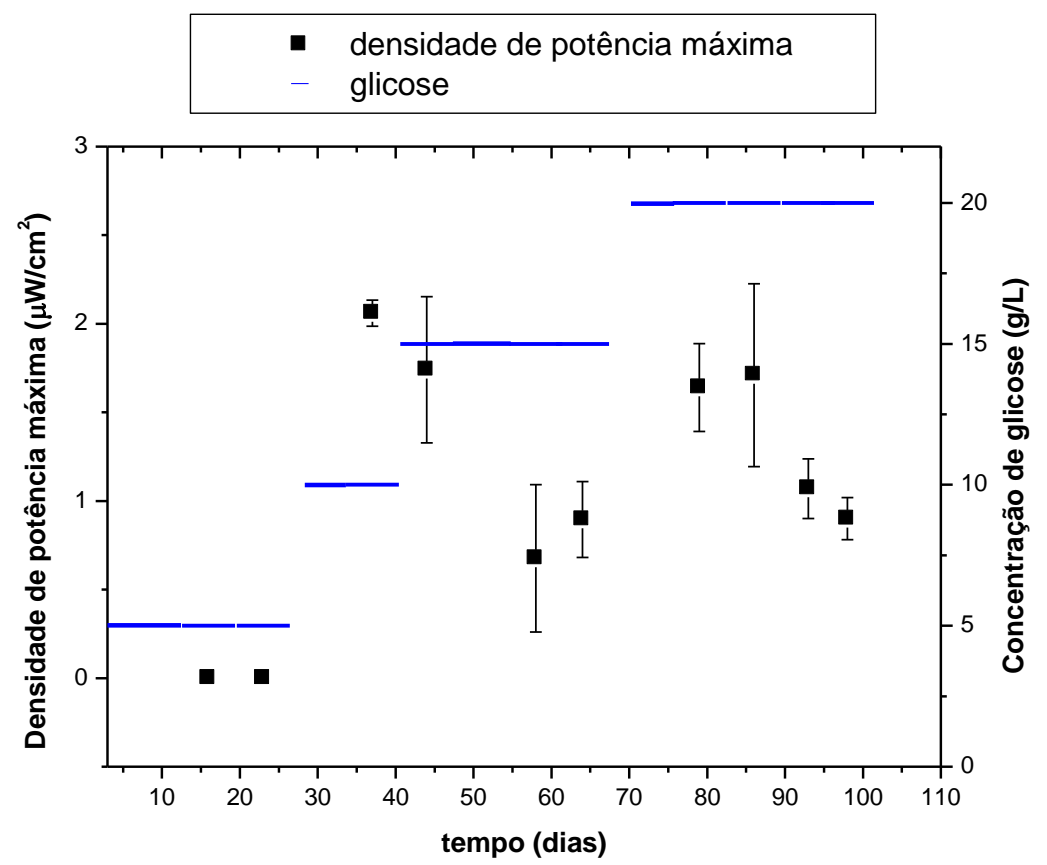

Figura 2. Densidade de potência e concentração de glicose ao longo do período de monitoramento dos biorreatores, com os desvios da média das triplicatas.

Yusoff et al. (2013) em seu trabalho, utilizando o lodo, obteve uma densidade de potência igual a $1 \mu \mathrm{W} \mathrm{cm} \mathrm{cm}^{-2}$. Tomando por base o pico conseguido durante esse experimento, obtivemos o dobro desta densidade de potência, ou seja, um valor de $2,06 \mu \mathrm{W} \mathrm{cm}{ }^{-2}$. Além disso, em revisão feita por Pant et al. (2010) são mostrados outros resultados utilizando-se os mais variados tipos de substrato, tais como acetato, butirato, biomassa lignocelulósica, águas residuárias domésticas, etc. Apesar da dificuldade de comparação destes resultados, pois as condições experimentais entre os trabalhos variam muito, os valores de densidade de potência variaram de $14,6 \mu \mathrm{W} \mathrm{cm}$ c $^{-2}$ a $50,6 \mu \mathrm{W}$ 
$\mathrm{cm}^{-2}$. Apesar do máximo valor de densidade de potência obtido neste trabalho ser inferior aos reportados na revisão de Pant et al. (2010), o mesmo é promissor, visto que o sistema utilizado neste trabalho foi operado de forma intermitente, ou seja, não permaneceu constantemente ligado ao potenciostato e ao cátodo. Desta forma os microrganismos não foram adaptados à liberação dos elétrons para fora da célula. Espera-se que a incorporação de uma sistema contínuo de medidas de corrente forneça um ambiente no qual os mesmos sejam capazes de realizar a transferência eletrônica de modo bem mais eficiente.

A Figura 3 mostra as concentrações dos ácidos orgânicos produzidos pelos microrganismos ao longo do tempo de monitoramento dos biorreatores. Foi observado que a concentração do ácido acético e butírico diminuíram com o aumento da concentração de glicose. Contrário a esse comportamento, o ácido lático sofreu um aumento, junto ao aumento da concentração de glicose. Desse modo, podemos dizer que a fermentação favorecida foi predominantemente a lática. $\mathrm{O} \mathrm{pH}$ dos biorreatores também decresceu com o aumento da concentração de glicose (dados não mostrados). A queda do $\mathrm{pH}$ é devido, provavelmente à formação de ácidos orgânicos, metabólitos da degradação anaeróbia da glicose.

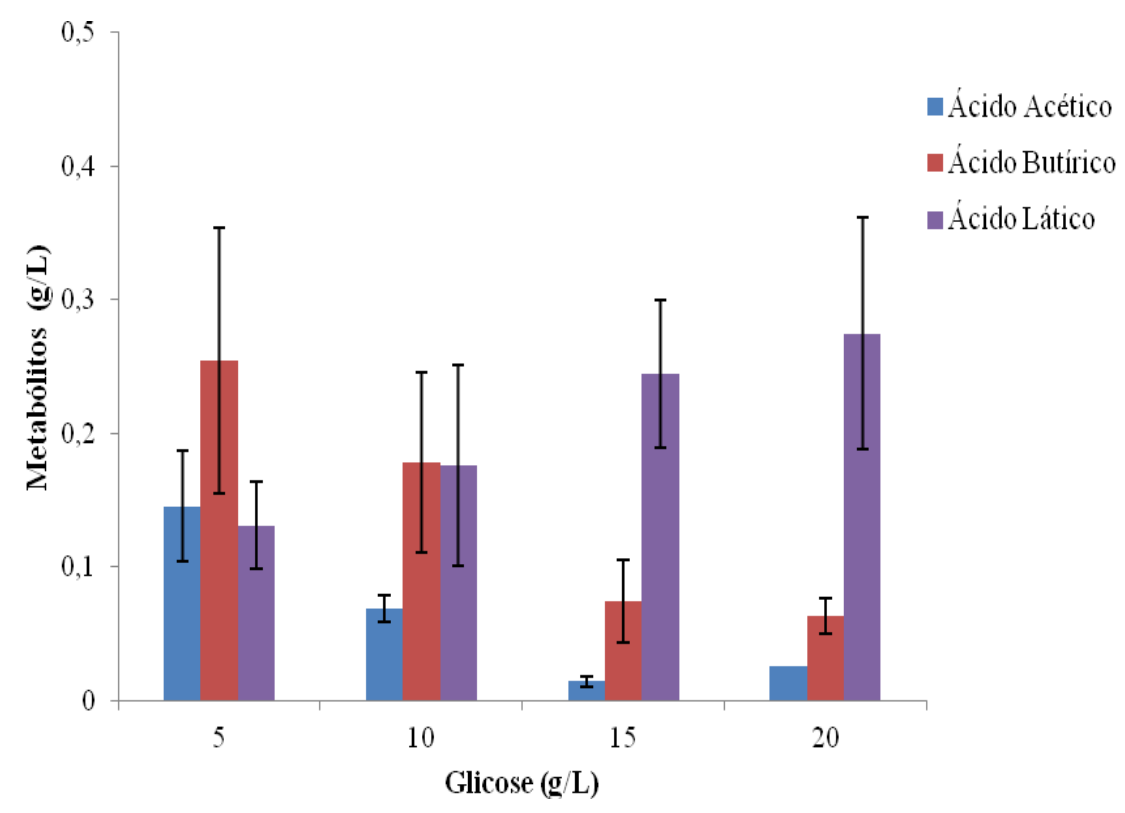

Figura 3. Concentração de ácidos orgânicos em diferentes concentrações de glicose aplicadas aos biorreatores.

Na Figura 4 pode ser observado o consumo de glicose em relação à concentração aplicada ao biorreator. Houve um aumento do consumo de glicose com o aumento da concentração aplicada aos biorreatores. Entretanto, o aumento do consumo de glicose não promoveu um aumento da densidade 
de potência, conforme pode ser visto na Figura 2. Provavelmente porque os elétrons obtidos pela oxidação da glicose não eram liberados para fora da célula.

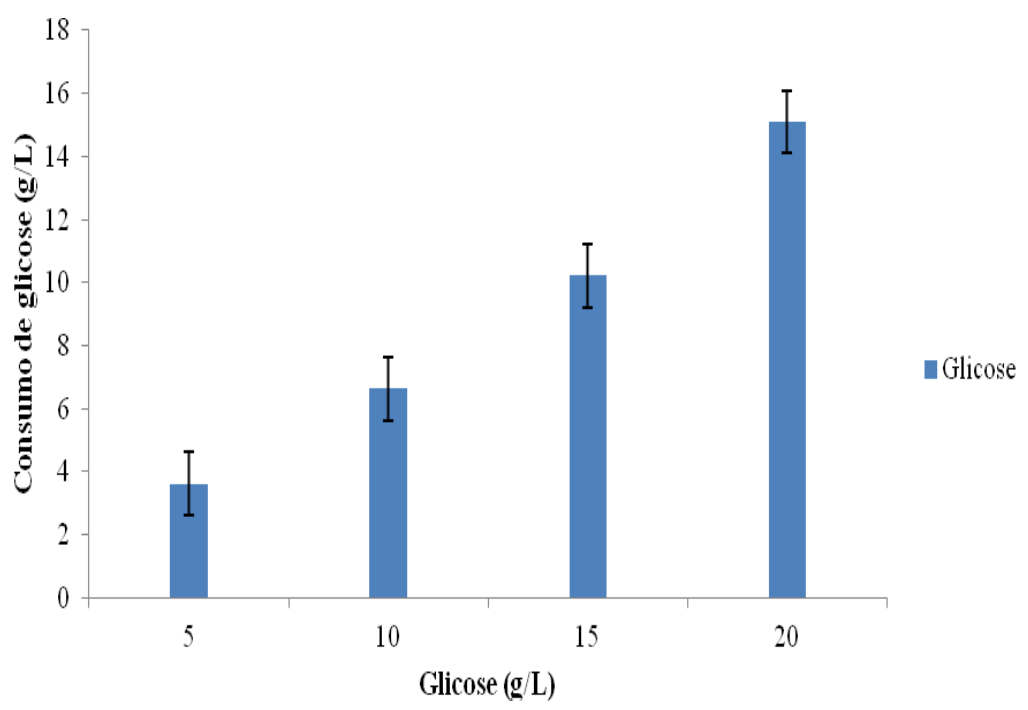

Figura 4. Consumo de glicose em diferentes concentrações de glicose aplicadas aos biorreatores.

\section{CONCLUSÕES}

Através deste trabalho é possível perceber que há uma vasta área de pesquisa a ser explorada para obtenção de energia pelas reações de oxi-redução realizada pelos microrganismos.

Foi observado que o biofilme possui uma característica de reciclagem dos microrganismos, ou seja, há um crescimento dos microrganismos do biofilme, com consequente aumento da potência, seguido por uma queda destes, diminuindo a potência.

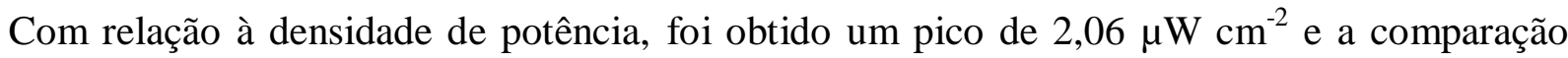
entre os dados de potência obtidos com relatos da literatura não é trivial, isto pois, existem algumas diferenças experimentais encontradas em cada trabalho. No entanto, os valores de densidade de potência obtidos neste trabalho foram promissores, em comparação com os resultados publicados em muitos dos recentes trabalhos relacionados a células microbianas à combustível.

Acredita-se que com a implementação de um sistema experimental que permita a retirada continua dos elétrons da oxidação de materiais orgânicos possa-se aumentar muito a densidade de potência observada neste trabalho. 


\section{REFERÊNCIAS}

APHA, AWWA, WEF. Standard methods for the examination of water and wastewater. 19th. edn. American Public Health Association. Washington, DC, 2005.

GONZALEZ-GIL, G.; KLEEREBEZEM, R.; LETTINGA, G. Assessment of metabolic properties and kinetic parameters of methanogenic sludge by on-line methane production rate measurements. Appl. Microbiol. Biotechnol. 58: 248-254, 2002. (modificado a quantidade de $\mathrm{N}$ e de $\mathrm{P}$, para perfazer $\mathrm{C} / \mathrm{N}=140$ e $\mathrm{C} / \mathrm{P}=133$ e tampão $\left(\mathrm{KH}_{2} \mathrm{PO}_{4}\right.$ e $\left.\mathrm{Na}_{2} \mathrm{HPO}_{4}\right)$.

LOGAN, B. E. Exoelectrogenic bacteria that power microbial fuel cells. Nature Reviews/Microbiology 7: 375-381, 2009.

MARCON, L. R. C.; MARQUES, A. F.; DANIEL, L. A. Emprego de células combustíveis microbianas na geração de energia elétrica. 2012.

MOEHLENBROCK, M. J.; MINTEER, S.; Extended lifetime biofuel cells. Chemical Society Reviews 37: 1188-1196, 2008.

PANT, D.; BOGAERT, G. V.; DIELS, L.; VANBROEKHOVEN, K. A review of the substrates used in microbial fuel cells (MFCs) for sustainable energy production. Bioresource Technology 101: 1533$1543,2010$.

PHAM, T. H.; RABAEY, K.; AELTERMAN, P.; CLAUWAERT, P.; SCHAMPHELAIRE, L.; DE BOON, N.; VERSTRAETE, W. Microbial fuel cells in relation to conventional anaerobic digestion technology. Eng. Life Sci. 6(3): 285-292, 2006.

RACHINSKI, S.; CARUBELli, A.; MANGONI, A. P.; MANGRICH, A. S. Pilhas de combustíveis microbianas utilizadas na produção de eletricidade a partir de rejeitos orgânicos: uma perspectiva para o futuro. Química Nova 33 (8): 1773-1778, 2010.

YUSOFF, M. Z. M.; HU, A.; FENG, C.; MAEDA, T.; SHIRAI, Y.; HASSAN, M. A.; YU, C. P. Influence of pretreated activated sludge for electricity generation in microbial fuel cell application. Bioresource Technology 145: 90-96, 2013. 